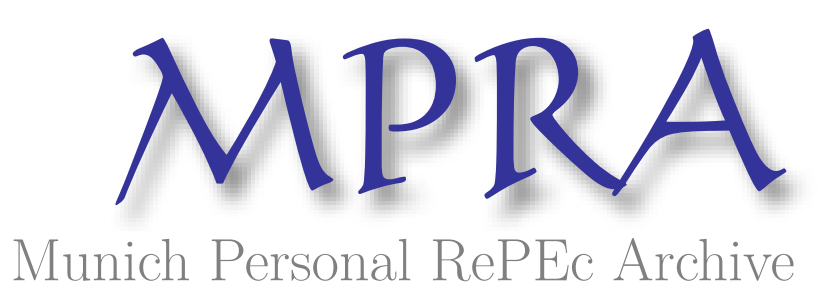

\title{
Auctions with Limited Liability through Default or Resale
}

Pagnozzi, Marco and Saral, Krista J.

Webster University Geneva, GATE Lyon St. Etienne

October 2009

Online at https://mpra.ub.uni-muenchen.de/85145/

MPRA Paper No. 85145, posted 12 Mar 2018 09:41 UTC 


\title{
Auctions with Limited Liability through Default or Resale*
}

\author{
Marco Pagnozzi ${ }^{\dagger} \quad$ Krista J. SaraL $^{\ddagger}$
}

March 11, 2018

\begin{abstract}
If bidders are uncertain about their value when they participate in an auction, they may overbid and suffer ex-post losses. Limited liability mitigates these losses, and may result in more aggressive bidding and higher seller revenue, but also in an inefficient allocation. Using a combination of theory and experiment, we analyze three different forms of liability in second-price auctions: full liability, limited liability by default with varying penalties, and resale-based limited liability. With a default penalty, bids are higher than under full liability, but final revenue and efficiency are lower due to the frequency of default. Auctions with resale result in the highest revenue and allocative efficiency, and are as effective as a low default penalty in alleviating bidders' losses. Hence, allowing resale as a form of limited liability may be preferred by both bidders and sellers over other liability rules.
\end{abstract}

JEL Codes: D44, C90

Key Words: Auctions, Limited Liability, Default, Resale, Experimental Economics

${ }^{*}$ We would like to thank the associate editor and the referee for extremely helpful suggestions, as well as seminar participants at GATE Lyon Saint-Etienne and ESA Copenhagen. We would also like to thank Tim Salmon for insightful comments.

${ }^{\dagger}$ Department of Economics and Statistics and CSEF, Università di Napoli Federico II, Via Cintia (Monte S. Angelo), 80126 Napoli, Italy. Email: pagnozzi@unina.it.

${ }^{\ddagger}$ George Herbert Walker School of Business and Technology, Webster University Geneva, Route de Collex 15, CH-1293 Bellevue, Switzerland, and CNRS, GATE Lyon St Etienne. Email: kjsaral@webster.ch. 


\section{Introduction}

It is common in many auctions that bidders are uncertain of their valuations for the item on sale when placing their bids. Examples range from auctions for second-hand items on eBay, auto salvage, foreclosure and commodities such as cotton or timber, where the quality of the item is uncertain, to large-scale spectrum auctions with uncertain future demand. ${ }^{1}$ When the value of an item cannot be easily verified prior to placing a bid, or when the exact value is realized only after the auction is concluded, bidders must choose their bids carefully. Even with meticulous planning, however, bidders may suffer losses if they overbid relative to their realized final value (e.g., Pagnozzi, 2007b).

Given the potential for overbidding and possible losses, liability rules stipulated by auction designers prior to the auction taking place have a significant effect on bidders' behavior and the final allocation. In his practical guide for auction design, Klemperer (2002) highlights the importance of properly structured default penalties: "If default costs are small, then bidders are bidding for options on prizes rather than the prizes themselves" (p.176).

In fact, the failure to properly design clear auction payment and default rules can have dramatic effects. For example, McMillan (1994) reports of an Australian auction for satellite television services where there was no penalty for default and the rules specified that the licenses were awarded to the next highest bid in the case of default. The unexpected "dark horse winners" gamed the auction by placing high winning bids that they had no intention of fulfilling, as well as other lower bids. After a series of defaults, the licenses were awarded for an amount substantially below the original highest bids, and one of the winners then resold for a profit. According to McMillan (1994), "The flaw in the auction rules, the source of the cascading bids, was the absence of a penalty for default, which meant bids were not meaningful" (p. 149).

However, how an auction designer should optimally set default penalties, or whether he should even allow default, is a nontrivial decision as different rules will have differing effects on bidding behavior and auction outcomes. In the field, a variety of different default and liability rules are observed, some of which appear to have been introduced in an ad hoc manner.

At one end of the liability spectrum, in some auctions bidders are allowed to default with no penalty, through bid retraction or even non-payment. For example, in the online marketplace eBay winning bidders can ask for a full bid retraction. ${ }^{2}$ At the other end of the liability spectrum, bidders are fully liable for any bid placed. While the bulk of auction research assumes full liability, enforcing full liability in practice is difficult, since it requires mechanisms to ensure full payment by winners, such as a refundable deposit equal to the maximum possible bid. With uncertain valuations, full liability leads to more conservative bidding because winning bidders have no outside option in the event of a loss. Full liability, however, may increase efficiency by limiting default.

\footnotetext{
${ }^{1} \mathrm{~A}$ similar uncertainty also arises when bidders purchase to resell in a secondary market.

${ }^{2}$ Winning bidders can also just refuse to pay. While this behavior is recorded by eBay which could result in future restrictions, no specific monetary penalty is imposed.
} 
Between the extremes of costless default and full liability, there are many common environments where default is allowed with a monetary penalty. For example, defaulting bidders in the FCC C-Block Auctions paid "a penalty equal to the difference between the amount bid and the amount of the winning bid the next time the license is offered by the Commission plus an additional penalty equal to 3 percent of the subsequent winning bid." ${ }^{3}$ In many other auctions, bidders make an initial deposit equal to a percentage of the maximum bid, which is forfeited in the event of default. For example, to participate in timber auctions in the U.S. state of Washington, bidders pay a deposit of $10 \%$, which is increased to $25 \%$ for previous defaulters. ${ }^{4}$ Since these penalties require a payment which is lower than the full amount owed, they might help winning bidders mitigate realized losses. Hence, the option of default may allow bidders to bid more aggressively, which raises (nominal) revenue but also increases the probability of an inefficient default. Clearly, the choice of a default penalty should balance the trade-off between revenue and the probability of default, which depends on the behavioral response by bidders.

All statutory limited liability elements are typically explicitly specified in the auction rules. In addition, a different and less obvious form of (non-statutory) limited liability for bidders arises through the opportunity to resell an item acquired in an auction, before having to pay the auction price. Resale is a common occurrence in a variety of auctions where bidders face uncertainty about their private valuations. ${ }^{5}$ In fact, once uncertainty over valuations is resolved, a winning bidder who realizes he paid more than his actual value is willing to resell to a new buyer with a higher value, thus limiting his losses or even making a total profit.

Therefore, allowing resale provides an outside option to auction winners who overpaid and create a form of limited liability. ${ }^{6}$ Essentially, while with default limited liability arises through the possibility of returning the item to the initial seller, with resale it arises through the possibility of exchanging it with another bidder. It follows that allowing resale may induce more aggressive bidding, thus increasing revenue without the threat of default. And it can also lead to efficiency gains since items are resold to higher-valued buyers.

Although bidders' theoretical response to outside options should result in more aggressive bidding with limited liability, their actual behavior across different liability rules may depend on a number of behavioral reasons. For example, bidders may differ in their risk tolerance or, with resale-based limited liability, they may be less sophisticated than theoretically assumed and therefore unable to integrate a resale opportunity into their strategies. Thus, it is unclear how actual bidders react to different limited liability environments, including those with more

\footnotetext{
${ }^{3}$ Source: C.H. PCS, Inc., BTA No. B347 Frequency Block C Order.

Retrieved: January 21, 2016 from http://wireless.fcc.gov/auctions/10/releases/da961825.pdf

${ }^{4}$ Source: Public Auction Sale of Timber, Book 965. July 2016.

Retrieved: February 27, 2018 from http://www.dnr.wa.gov/publications/psl_ts_jul16_auctionbook.pdf

${ }^{5}$ See e.g. Haile (2001) for an analysis of resale after timber auctions, and Haile (2003) for a general analysis of private value uncertainty and resale.

${ }^{6}$ While in reality restricting post-auction resale may be difficult, there are various auctions where resale is not allowed. For example, resale was explicitly forbidden in the early U.S. spectrum auctions conducted by the FCC, and in European countries. More recently, the FCC has relaxed restrictions on resale, but may impose penalties for transactions taking place less than 5 years after the auction (see 47 C.F.R. section 1.2111 of the FCC).
} 
nuanced incentives such as resale or high default penalties. ${ }^{7}$

In order to address these issues, we analyze how bidding behavior and auction outcomes change across different liability environments, using a combination of theory and economic experiments. We consider a second price auction with two risk neutral bidders who observe a private signal of their value, which then becomes known at the conclusion of the auction. Three different settings are compared: full liability, limited liability induced through default with a penalty payment, and resale-based limited liability. The baseline environment is full liability, where the winner always pays the auction price. In the limited liability environment the winner can default by paying a percentage of the auction price, while with resale-based limited liability the winner can resell the item to a losing bidder after the auction.

In theory, bidding in all limited liability treatments should be more aggressive than with full liability, with the strongest differences for lower private signals. For higher private signals, predicted differences between liability rules are less stark and, depending on the default penalty, bidding may be equivalent to full liability.

Our experiment consists of four treatments: Full Liability, 5\% Default, 25\% Default, and Resale. These treatments mimic the theoretical environment and were designed to ensure tight control over decisions to accurately test the response of bidders to varying liability rules. In the default treatments, the winning bidder was forced to default whenever his loss in the auction was lower than the loss with default, by paying either a $5 \%$ or a $25 \%$ default penalty. In the resale treatment, whenever the winner had a lower realized value than the loser, the item was transferred to the loser at a resale price equal to his value. We introduce these controls over decisions (which abstract from real world scenarios where default is a choice and resale involves a less structured process) in order to cleanly test bidders' reaction to the default and resale environments, without confounds such as profitable default or resale failing to occur because of bidders' mistakes. ${ }^{8}$

We find that bidding behavior does vary across different liability environments. In support of the theoretical predictions, bidding behavior is most aggressive in the $5 \%$ default treatment. We also find that bidders are able to integrate the incentives of the resale market into their bidding decisions, which results in higher bids, but the effect of resale weakens over time. So we have partial support of the theory in the case of resale-based limited liability. In contrast to predictions, we find that bidding behavior under a high default penalty $(25 \%)$ is similar to full liability, so bidders only react to limited liability induced through default when the penalty is relatively low.

These results indicate that bidders are sensitive to the type of liability environment they face

\footnotetext{
${ }^{7}$ Previous studies (Roelofs, 2002, and Onderstal and Van der Veen, 2011) find empirical evidence that bidders respond to strong limited liability incentives (full costless default or very low penalties) compared to a full liability baseline.

${ }^{8}$ For example, if bidders failed to respond to the incentives of a more flexible resale market it would be unclear if they were not responding because of beliefs that the resale market would fail, or because they misunderstood the limited liability incentives of resale.
} 
in an auction, but in contrast to theoretical predictions they do not always respond to limited liability by bidding more aggressively. Roelofs (2002) and Onderstal and Van der Veen (2011) provide previous experimental evidence of more aggressive bidders' behavior but consider full default and a low and fixed default penalty, respectively. Hence, their results are in-line with the behavior observed under a low default penalty in our experiment.

Turning to seller revenue, while bids are observed to be highest under the $5 \%$ default rule, the final revenue achieved in this case was often lower due to the prevalence of default. Consequently, revenue is highest in the resale treatment. The resale treatment also resulted in the highest allocative efficiency. From the bidder's perspective, average earnings are essentially equivalent across all environments (including full liability). Conditional on making a loss, resale or a low default penalty $(5 \%)$ were most effective at mitigating losses.

Therefore, our results suggest that resale may be the preferred limited liability mechanism by both sellers and bidders. The reason is that, in addition to allowing bidders to limit losses once uncertainty over their valuations is realized, resale also allows to correct an inefficient allocation of the item achieved in the auction due to this uncertainty, while default does not and may even increase inefficiency by delaying the final allocation to the bidder with the highest value.

The rest of the paper is organized as follows. After a brief discussion of the related literature, in the next section we present the theoretical predictions. Section 3 describes the design of the experiment. Section 4 discusses the experiment results and the last section concludes.

Related Literature. This paper contributes to the literature on limited liability in auctions. A number of theoretical papers have established that changing the liability of a bidder changes the underlying incentives of the auction which affects bidding behavior and ultimately, auction outcomes. For example, Waehrer (1995) demonstrates that under a bid deposit, which is the maximum payment required under default, bids become more aggressive as the deposit amount is decreased which also leads to higher levels of default. Harstad and Rothkopf (1995) examine the possibility of bid withdrawals, also finding more aggressive bidding under this scheme. Zheng (2001), Pagnozzi (2007a), and Board (2007) analyze limited liability induced through wealth constraints where capped downside losses (due to lower initial wealth) result in more aggressive bidding behavior and inefficient allocations. Similar results have also been established in the procurement setting (e.g., Roelofs, 2002; Parlane, 2003; Burguet et al., 2012). While more aggressive bidding should lead to higher revenues; it's not necessarily the case that sellers are better off since the winning bidder may default, particularly if sellers are unable to fully recover items (Board, 2007).

On the experimental side, to our knowledge, only two papers deal with limited liability rules in the auction setting. ${ }^{9}$ Roelofs (2002) examines a common value procurement auction with

\footnotetext{
${ }^{9}$ Other experimental papers have addressed the possibility of default and limited liability, in a different sense. Limited liability created by budget constraints was examined by Hasen \& Lott (1991) in a comment regarding the design of Kagel \& Levin (1986). A typical constraint faced in economic experiments, and the issue raised by Hasen \& Lott, is that subjects cannot make losses. Therefore, subjects with low cash balances have limited
} 
full (costless) default, finding empirical evidence that bidders do choose to bid more aggressively when default is allowed, but mixed evidence on the effectiveness of the theory to predict behavior. Onderstal and Van der Veen (2011) analyze first and second price auctions with a fixed penalty in the event of default finding that bidders react more aggressively than theory predicts to the presence of limited liability. Our paper differs from both of these studies in three important ways: (i) differences across limited liability formats are examined (ii) resale is introduced as a market-based form of limited liability (iii) the default penalty is changed to a percentage-based penalty, and responses to the level of the penalty are also examined.

\section{Theoretical Analysis}

\section{Model}

In this section, we construct a simple model that provides the framework to experimentally investigate the effects of different liability environments on bidding strategies and auction outcomes. We consider a (sealed-bid) second-price auction for one item, with no reserve price: bidders simultaneously submit a bid for the item; the highest bidder is awarded the item and pays a price equal to the second-highest bid.

There are 2 risk-neutral bidders. The final use value for the item for the seller is 0 , while the final use value for bidder $i$ is

$$
v_{i} \equiv x_{i}+\varepsilon_{i}, \quad i=1,2 .
$$

Prior to the auction, bidder $i$ observes the private signal $x_{i}$ which is drawn from a uniform distribution on the support $[0, \bar{x}]$. However, the bidder does not know $\varepsilon_{i}$, an idiosyncratic and uncertain component of his valuation, which is equal to 0 with probability $\frac{1}{2}$, and is equal to $\bar{\varepsilon}$ with probability $\frac{1}{2}$. All signals and use values are independent.

Therefore, the final use value of bidder $i, i=1,2$, is

$$
v_{i}= \begin{cases}x_{i} & \text { with probability } \frac{1}{2}, \\ x_{i}+\bar{\varepsilon} & \text { with probability } \frac{1}{2},\end{cases}
$$

and

$$
\mathbb{E}\left[v_{i}\right]=x_{i}+\frac{\bar{\varepsilon}}{2} .
$$

After the auction, both bidders learn both use values - i.e., $v_{1}$ and $v_{2}$ become common knowledge. ${ }^{10}$

liability because the downside loss is capped at zero. Kagel \& Levin (1991) respond to this comment with how they controlled for limited liability by providing cash endowments to the subjects that covered the maximum possible loss. Budget constraints can also be viewed as a form of market-based limited liability, but this type of liability is not examined in this paper.

${ }^{10}$ The assumption that a bidder learns the use value of his opponent simplifies the analysis of the resale market but does not affect our qualitative results. 
This valuation structure captures an environment where bidders are uncertain about their exact valuations when they participate in the auction, but this uncertainty is resolved after the auction. Therefore, the auction winner may end up paying more than his valuation for the item on sale, and realize it after the auction terminates. In this case, the auction winner may prefer not to keep the item and pay the auction price, if he is protected by some form of limited liability.

We consider three different liability environments after the auction:

1. Full Liability: the winning bidder must pay the entirety of the auction price to the seller.

2. Statutory Limited Liability through Default: the winning bidder can default (after learning his use value), return the item to the seller and only pay a fraction $\alpha \in(0,1)$ of the auction price to the seller.

3. Market-Based Limited Liability through Resale: the winning bidder cannot default but can resell the item to the losing bidder, by making a take-it-or-leave-it offer. ${ }^{11}$

While many other resale mechanisms yield qualitative predictions that are similar to the ones that we will describe, our set-up provides a clean framework to analyze the response of bidders to the limited liability aspects of a resale opportunity, which is our primary topic of interest. With this modelling choice, the resale market yields the highest profit to the winning bidder, since he can make a take-it-or-leave-it offer equal to the value of the losing bidder, thus obtaining the whole resale surplus. Therefore, bidders' response to resale-based limited liability should be strongest in our environment.

We focus on symmetric equilibrium bid strategies, that are increasing in bidders' private signals.

\section{Full Liability}

With full liability, if bidder $i$ wins the auction at price $p$, he earns an expected profit equal to $\mathbb{E}\left[v_{i}\right]-p$; while if he loses the auction, he earns 0 . Therefore, in a second-price auction bidder $i$ bids a price such that his expected profit from winning is equal to zero - i.e.,

$$
b_{F}^{*}\left(x_{i}\right)=x_{i}+\frac{\bar{\varepsilon}}{2}, \quad i=1,2 .
$$

The bidder with the highest private signal wins the auction and the allocation is inefficient whenever bidder $i$ wins but $v_{j}>v_{i}$ - i.e., with probability $\frac{\bar{\varepsilon}}{4 \bar{x}} \cdot{ }^{12}$ Moreover, the auction winner obtains negative profit whenever the bid of his competitor is higher than its use value.

\footnotetext{
${ }^{11}$ This is similar to the resale market structure analyzed by Calzolari and Pavan (2006), for example, who assume that the proposer of the take-it-or-leave-it offer is chosen randomly.

${ }^{12}$ This is the probability that $\varepsilon_{i}=0$ and $\varepsilon_{j}=\bar{\varepsilon}$ and $x_{j}<x_{i}<x_{j}+\bar{\varepsilon}$.
} 
Specifically, bidder $i$ obtains negative profits when $\left(x_{j}+\frac{\bar{\varepsilon}}{2}\right) \in\left[x_{i}, x_{i}+\frac{\bar{\varepsilon}}{2}\right]$ and $\varepsilon_{i}=0$ - i.e., with probability $\frac{\bar{\varepsilon}}{4 \bar{x}} \cdot{ }^{13}$

\section{Limited Liability through Resale}

Suppose now that the winning bidder can resell. With symmetric and increasing bidding functions, bidder $i$ wins the auction if and only if $x_{i}>x_{j}$ and resells to bidder $j$ (by making an offer equal to $v_{j}$ ) if and only if

$$
v_{j}>v_{i} \Leftrightarrow \varepsilon_{j}>x_{i}-x_{j}+\varepsilon_{i}
$$

Therefore, conditional on bidder $i$ winning the auction, resale requires that: $(i) \varepsilon_{j}=\bar{\varepsilon}$, $(i i)$ $\varepsilon_{i}=0$, and $(i i i) x_{i}-x_{j}<\bar{\varepsilon}$.

In a second-price auction, bidder $i$ bids a price equal to his expected profit from winning the auction (because if he loses, he obtains zero even if he buys from the auction winner) - i.e.,

$$
\begin{gathered}
\mathbb{E}\left[\pi_{i} \mid i \text { wins }\right]=\operatorname{Pr}[\text { no resale } \mid i \text { wins }] \times \mathbb{E}\left[v_{i} \mid i \text { wins and does not resell }\right]+ \\
\operatorname{Pr}[\text { resale } \mid i \text { wins }] \times \mathbb{E}[\text { resale price } \mid i \text { wins and resells }]
\end{gathered}
$$

In the Appendix, we show that the equilibrium bidding function with resale is

$$
b_{R}^{*}\left(x_{i}\right)= \begin{cases}\frac{7}{8} x_{i}+\frac{3}{4} \bar{\varepsilon} & \text { if } x_{i}<\bar{\varepsilon}, \\ x_{i}+\frac{\bar{\varepsilon}}{2}+\frac{\bar{\varepsilon}^{2}}{8 x_{i}} & \text { if } x_{i}>\bar{\varepsilon}\end{cases}
$$

Since the winning bidder has the option of reselling the item to the losing bidder who may have a higher use value, this provides a form of limited liability in the event that the winning bidder turns out to have a low value. The resale option can mitigate losses at the conclusion of the auction (if the auction price is higher than the realized value of the winner) or increase the profit of the winner bidder (when there are gains from trade in the resale market). Consequently, in the auction, a bidder is willing to bid a price that reflects the value of this option (i.e., the expected resale price) and equilibrium bidding behavior is therefore more aggressive than with full liability: $b_{R}^{*}\left(x_{i}\right)>b_{F}^{*}\left(x_{i}\right)$. Moreover, compared to the case with full liability, with resale the seller's revenue is higher and the final allocation is always efficient.

In our experiments, we let $\bar{x}=50$ and $\bar{\varepsilon}=20$, so that the equilibrium bidding function with resale is

$$
b_{R}^{*}\left(x_{i}\right)= \begin{cases}\frac{7}{8} x_{i}+15 & \text { if } x_{i}<20 \\ x_{i}+\frac{50}{x_{i}}+10 & \text { if } x_{i}>20 .\end{cases}
$$

Figure 2.1 plots the bidding functions $b_{R}^{*}\left(x_{i}\right)$ and $b_{F}^{*}\left(x_{i}\right)$ (for $\bar{x}=50$ and $\bar{\varepsilon}=20$ ).

\footnotetext{
${ }^{13}$ In this case, bidder $i$ has value is $x_{i}$ and wins the auction, but the auction price is $x_{j}+\frac{\bar{\varepsilon}}{2}>x_{i}$.
} 


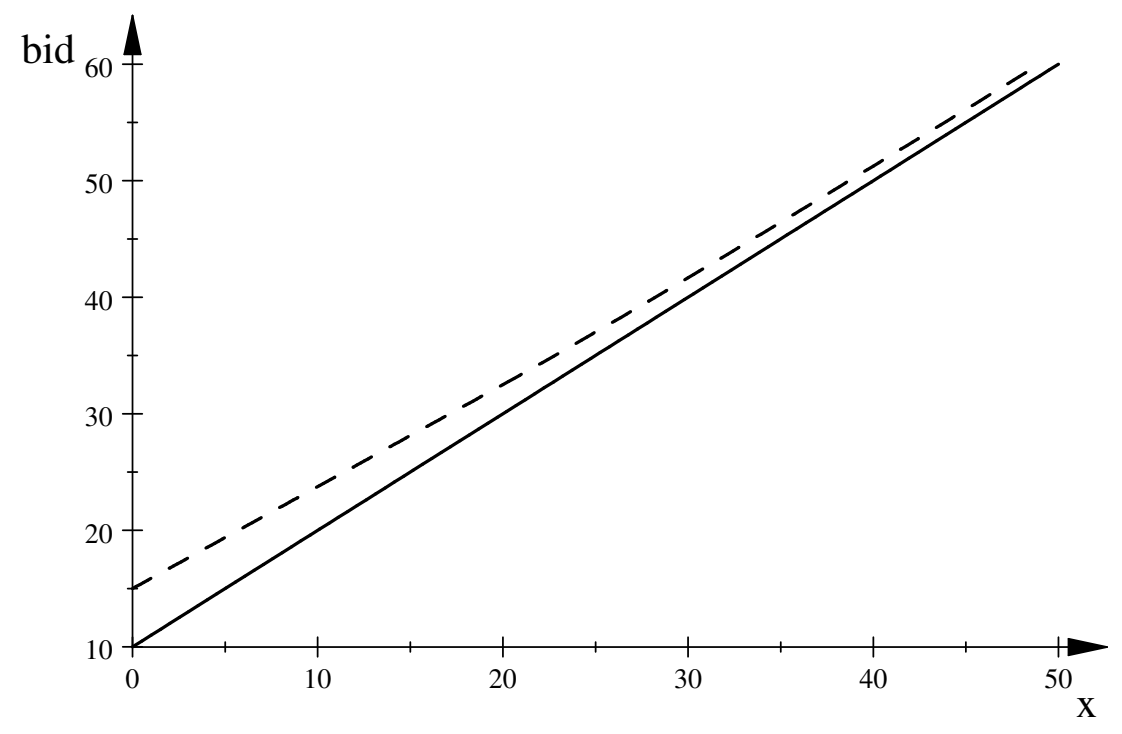

Figure 2.1: Bidding functions with Full Liability (solid) and with Limited Liability through Resale (dashed).

\section{Limited Liability through Default}

If a bidder defaults after winning the auction, he returns the item to the seller and pays a penalty which is a percentage $\alpha$ of the auction price. Therefore, a bidder chooses to default after winning the auction at price $p$ if and only if his profit from keeping the item and paying the auction price is lower than the default penalty - i.e.,

$$
v_{i}-p<-\alpha p \quad \Leftrightarrow \quad v_{i}<(1-\alpha) p
$$

and the actual profit of the auction winner is

$$
\max \left\{v_{i}-p ;-\alpha p\right\}
$$

The choice to default critically depends on $\alpha$. As $\alpha \rightarrow 1$, the profit converges to the full liability case and bidders never choose to default. As $\alpha$ decreases, default becomes more attractive for the winning bidder. As $\alpha \rightarrow 0$, we have the strongest form of limited liability: the winner always defaults when $v_{i}<p$ and never earns negative profit. In the Appendix, we show that a bidder defaults if and only if $\varepsilon_{i}=0$ and

$$
x_{i}<x^{*} \equiv \frac{(1-\alpha) \bar{\varepsilon}}{2 \alpha} .
$$


The equilibrium bidding function with default is

$$
b_{D}^{*}\left(x_{i}, \alpha\right)= \begin{cases}\frac{x_{i}+\bar{\varepsilon}}{1+\alpha} & \text { if } x_{i}<x^{*} \\ x_{i}+\frac{\bar{\varepsilon}}{2} & \text { if } x_{i} \geq x^{*}\end{cases}
$$

When a bidder's private signal is sufficiently high, the bidder never chooses to default and bids as with full liability. By contrast, when a bidder's private signal is low, he bids a percentage of his highest possible value and more aggressively than with full liability. The reason is that the bidder knows he can cut down his losses in case the realization of the idiosyncratic component is low: he has the option of giving up an item with low value and only pay a fraction of the auction price. Therefore, $b_{D}^{*}\left(x_{i}, \alpha\right) \geq b_{F}^{*}\left(x_{i}\right)$.

Notice that the degree of a bidder's aggressiveness with default is inversely related to the penalty $\alpha$ : the higher the penalty, the lower the equilibrium bid. Moreover, the threshold $x^{*}$ is decreasing in $\alpha$ : the higher the penalty, the easier it is that the bidder does not choose to default, so that the bidder bids more aggressively due to limited liability for lower values only.

Of course, if the winner defaults and returns the item to the seller, then the allocation is inefficient. Assuming that $x^{*} \geq 1$, this happens whenever bidder $i$ wins the auction but $\varepsilon_{i}=0$ - i.e., with probability $\frac{1}{4}$. Hence, the probability of a final inefficient allocation is higher than with full liability if and only if $\bar{x}>\bar{\varepsilon}$.

With the parameters used in our experiment, the bidding function with default is

$$
b_{D}^{*}\left(x_{i}, \alpha\right)= \begin{cases}\frac{1}{1+\alpha}\left(x_{i}+20\right) & \text { if } x_{i}<\frac{10(1-\alpha)}{\alpha} \\ x_{i}+10 & \text { if } x_{i} \geq \frac{10(1-\alpha)}{\alpha}\end{cases}
$$

In the experiment, we implement two default treatments: one with a high penalty $\alpha=0.25$; and one with a low penalty $\alpha=0.05$. When $\alpha=0.05$, bidders always bid more aggressively than with full liability (since $x^{*}=190$, which is higher than the maximum private signal). When $\alpha=0.25, x^{*}=30$ and the equilibrium bid function is kinked: bidders with high private signals bid as with full liability and bidders with low private signals bid more aggressively than with full liability (but less than with $\alpha=0.05$ ).

Figure 2.2 plots the bidding functions $b_{D}^{*}\left(x_{i}, 0.25\right), b_{D}^{*}\left(x_{i}, 0.05\right)$, and $b_{R}^{*}\left(x_{i}\right)$ for comparison. Notice that $b_{D}^{*}\left(x_{i}, 0.05\right)>b_{R}^{*}\left(x_{i}\right)$, while $b_{D}^{*}\left(x_{i}, 0.25\right)>b_{R}^{*}\left(x_{i}\right)$ if and only if $x_{i}$ is sufficiently low. ${ }^{14}$

\section{Theoretical Predictions}

Summing up, the theoretical predictions for our experiments are as follows:

Result 1. Bids and auction prices are higher with a low default penalty than with resale, and are higher with resale than with full liability - i.e., $b_{D}^{*}\left(x_{i}, 0.05\right)>b_{R}^{*}\left(x_{i}\right)>b_{F}^{*}\left(x_{i}\right)$.

\footnotetext{
${ }^{14}$ In fact, $\frac{4}{5}\left(x_{i}+20\right)<\frac{7}{8} x_{i}+15 \Leftrightarrow x_{i}>\frac{40}{3}$.
} 


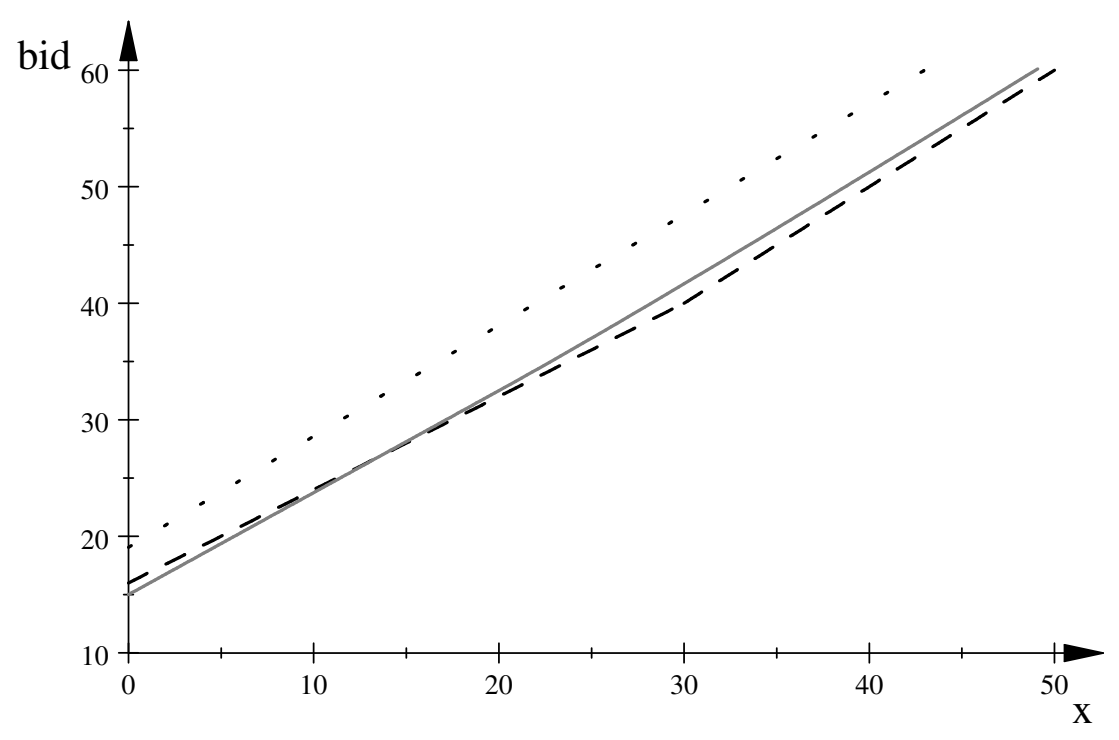

Figure 2.2: Bidding functions with Low Default Penalty (dotted), with High Default Penalty (dashed) and with Limited Liability through Resale (solid grey).

Result 2. Bids and auction prices are higher with a low default penalty than with a high default penalty,and are (weakly) higher with a high default penalty than with full liability - i.e., $b_{D}^{*}\left(x_{i}, 0.05\right)>b_{D}^{*}\left(x_{i}, 0.25\right) \geq b_{F}^{*}\left(x_{i}\right)$.

Result 3. Bidders with low (high) private signals bid higher (lower) with a high default penalty than with resale - i.e., $b_{D}^{*}\left(x_{i}, 0.25\right)>b_{R}^{*}\left(x_{i}\right)$ if and only if $x_{i}<\frac{40}{3}$.

Result 4. The probability of a final inefficient allocation of the item on sale is 0 with resale, and is higher with a low default penalty than with full liability.

\section{Experiment Design}

The experiments are designed to analyze bidding behavior and auction outcomes under four differing liability treatments. The baseline full liability treatment requires winning bidders to keep the item and pay the full auction price, even when making losses. The three remaining treatments introduce forms of limited liability that vary between a high default penalty where bidders are liable for $25 \%$ of the auction price if they default, a low default penalty where bidders only pay $5 \%$ of the auction price under default, and a resale treatment where trading automatically takes place in a post-auction resale market if the auction winner does not have the highest value.

In all treatments, each round began with a second-price (clock) auction with 2 bidders bidding for a hypothetical item of uncertain value. ${ }^{15}$ Each bidder observed a signal of the value,

\footnotetext{
${ }^{15}$ The use of a clock auction is based on previous experimental evidence that a clock improves subject understanding of bidding strategies (e.g., Bernard, 2006).
} 
$x_{i}$, independently drawn from a uniform distribution on $[0,50]$. The final use value of a bidder was determined through an independent 50/50 lottery over two possible use values: $x_{i}$ or $x_{i}+20$. During the auction, bidders knew the distribution of signals, their own draw, and distribution of final use values.

Bidders participated in the auction through a computer interface showing a bid clock increasing from 0 in increments of 1 . The clock represented the current price and subjects chose to "drop out" at a price that they were not willing to pay. In contrast to a more typical implementation of an ascending auction, subjects were not made aware of the dropout price of their opponent and the auction only ended when both bidders dropped out. The winner was the subject who dropped out last, and the auction price was equal to the first dropout bid. ${ }^{16}$ If neither subject dropped out, the auction automatically ended at a price of 70 , the maximum possible final use value. Ties were broken randomly by the computer software.

At the conclusion of the auction, the final use values were randomly drawn by the computer software. A bidder who won the item earned the difference between his final value and the auction price. In the default penalty treatments, if the winning bidder was making losses he would automatically default if the penalty payment under default, which was a percentage of the auction price, was less than the loss from not defaulting. In the resale treatment, (regardless of whether he was making losses) a winning bidder who did not have the highest value automatically traded the item at a resale price equal to the highest realized value. The winning bidder would then earn the difference between the resale price and the auction price. While alternative, nonautomated, bargaining mechanisms for resale could have been used (e.g., free-form bargaining), our design allowed us to keep experimental control over the resale market. ${ }^{17}$

The treatments are summarized below:

- Full Liability (F): The winner is fully liable for all losses in the event that earnings are negative.

- Resale (R): If the losing bidder has a higher realized final value than the winner, the winner automatically resells to the losing bidder at a price equal to the losing bidder's value.

- 5\% Default (D5\%): If by paying the auction price the winner would make a loss higher than the default penalty, he automatically defaults and pays $5 \%$ of the auction price.

- 25\% Default (D25\%): If by paying the auction price the winner would make a loss higher than the default penalty, he automatically defaults and pays $25 \%$ of the auction

\footnotetext{
${ }^{16}$ This dynamic implementation of the second-price auction has the major advantage of allowing us to observe the bids of both subjects in an auction, rather than just the losing bid.

${ }^{17}$ For example, it is known that in less structured resale procedures subjects often split the resale surplus more favorably than predicted in a take-it-or-leave framework, and resale sometimes fails to occur because of disagreement (Pagnozzi and Saral, 2017). Under these less controlled resale mechanisms, if subjects bid less aggressively it is unclear whether they choose to do so because they do not understand the limited liability aspects of resale or because they believe they cannot obtain any resale surplus.
} 


\begin{tabular}{lcc}
\hline & Sessions (Independent Subsessions) & Subjects \\
\hline F / R & $2(4)$ & 32 \\
F / D5\% & $2(4)$ & 32 \\
F / D25\% & $2(4)$ & 32 \\
\hline Session Structure & & \\
\hline Rounds 1-5 & F \\
Rounds 6-10 & R, D5\%, or D25\% \\
Rounds 11-20 & F \\
Rounds 21-30 & R, D5\%, or D25\% \\
\hline
\end{tabular}

Table 3.1: Experimental sessions and round structure

price.

Subjects were students at Florida State University recruited using ORSEE (Greiner, 2004). At the start of the experiment, they ran through the Holt and Laury (HL) (2002) risk preferences procedure, and one of the choices was randomly chosen for payment. Prior to the beginning of each treatment, subjects were given instructions that included an example of bidding behavior, and the opportunity to participate in one unpaid practice period against a computerized robot bidder. All subjects participated in 30 paid auction rounds. In the first ten rounds subjects participated in the full liability baseline ( 5 periods) followed by one of the limited liability treatments ( 5 periods). The last rounds were 10 periods of the full liability baseline, followed by 10 periods of a limited liability treatment. Table 3.1 summarizes the treatment and session structure.

We ran a total of 6 sessions, with 16 participants per session divided into 2 groups for random rematching of partners in each period, leading to two independent groups (subsessions) per session. In the results section, the analysis is performed with clustering at the subsession level since this is the first level of independence. The same value draws were used in all treatments. The experiment was programmed using Z-tree software (Fischbacher, 2007). Subjects' earnings were denominated in experimental currency units (ECUs), exchanged into dollars at a rate of $\$ 0.04$ per ECU. Subjects were given an endowment of 150 ECUs, from which losses and profits were tallied. The earnings from the HL procedure were not included in this endowment. Average earnings of the subjects were $\$ 28.16$, including the show-up fee of $\$ 10$ and HL earnings.

\section{Results}

We now describe the main experimental results. Section 4.1 presents summary statistics. The remaining sections provide formal regression analysis and statistical tests of the observed regularities: Section 4.2 considers bidding behavior, while Section 4.3 discusses revenue, efficiency, and earnings. 


\subsection{Summary Statistics}

We begin with summary statistics that provide a broad picture of the main treatment effects. In our analysis, we differentiate between results based on data from all periods and results based on data restricted to the last 20 periods (last 20).

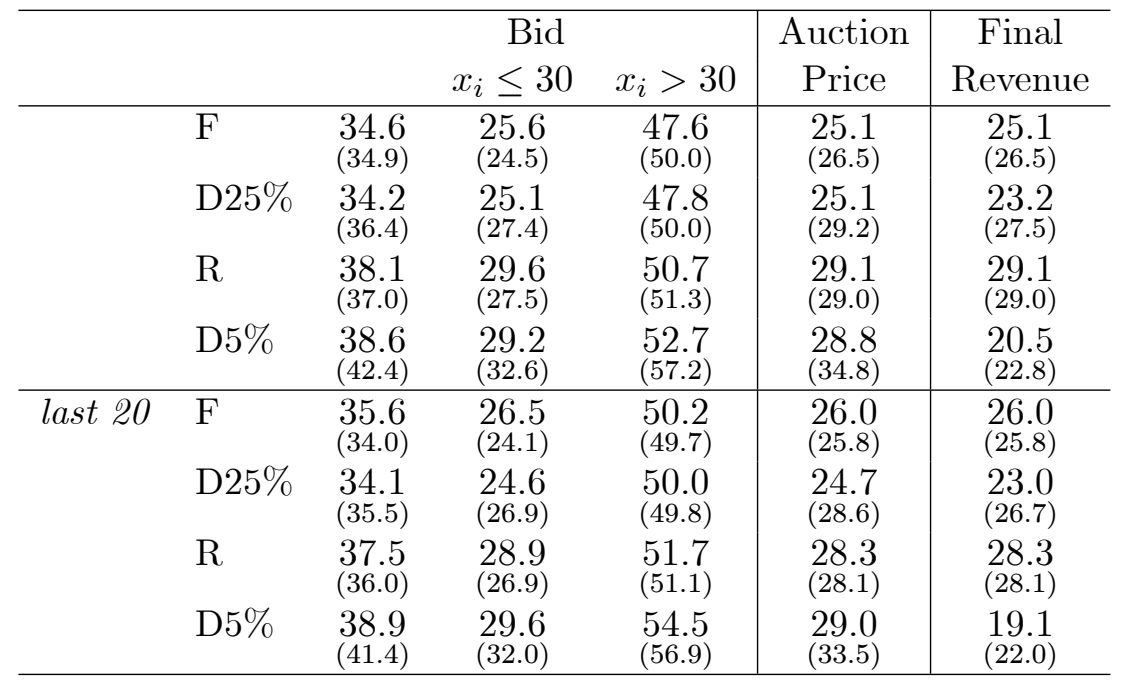

Table 4.1: Average observed bids, prices, and revenue. Theoretical predictions in parentheses.

Table 4.1 summarizes observed average bids, auction prices, and final seller revenue across treatments. We include in parentheses the predicted averages based on the signal draws used in the experiment. The results are presented from the lowest to the highest predicted bid (F to D5\%). Observed average bids in the $\mathrm{R}$ and D5\% treatments are higher than the full liability baseline, in line with the theoretical predictions. In the D25\% treatment, bids are roughly equivalent to those with full liability, even when separating low $\left(x_{i} \leq 30\right)$ and high signals $\left(x_{i}>30\right)$. So observed behavior with a high default penalty is not more aggressive than with full liability (as was predicted for low signals).

Comparing the observed results to the point predictions, for low signals, bids are relatively close to the prediction under full liability, higher than predicted under resale, and lower than predicted in both default treatments. So resale results in the highest average bids for lower signals, which is in contrast to the prediction of highest average bids under D5\%. For high signals, observed averages are always lower than predicted, with the least deviation in the resale case. More generally, the comparison demonstrates more similarity between the F and D25\% treatments for all private signals, rather than D25\% and R as predicted. Restricting the data to the last 20 periods, average bids for higher signals increase, indicating some learning in the direction of the theory. This effect is not observed for lower signals except in the full liability treatment.

Auction prices equal the first drop out bid in a group and are highest in the resale and $5 \%$ default treatments, mirroring the results for average bids. In contrast to the theoretical 
predictions, average auction prices are slightly higher in the resale treatment than in the $5 \%$ default treatment. Restricting the data to the last 20 periods reverses this ranking, but the differences between the two treatments remain small.

The final revenue earned by the seller in the auction takes into account default and it is equal to the percentage of the auction price paid by the winner in case of default, and to the auction price otherwise (i.e., in the resale, full liability, and default treatments with no default). The theoretical predictions are based on the realized final draws from the experiment. As expected, default lowers revenue compared to the auction price, especially in the D5\% treatment. The resale treatment results in the highest revenue, while revenue in the two default treatments is lower than in the full liability baseline.

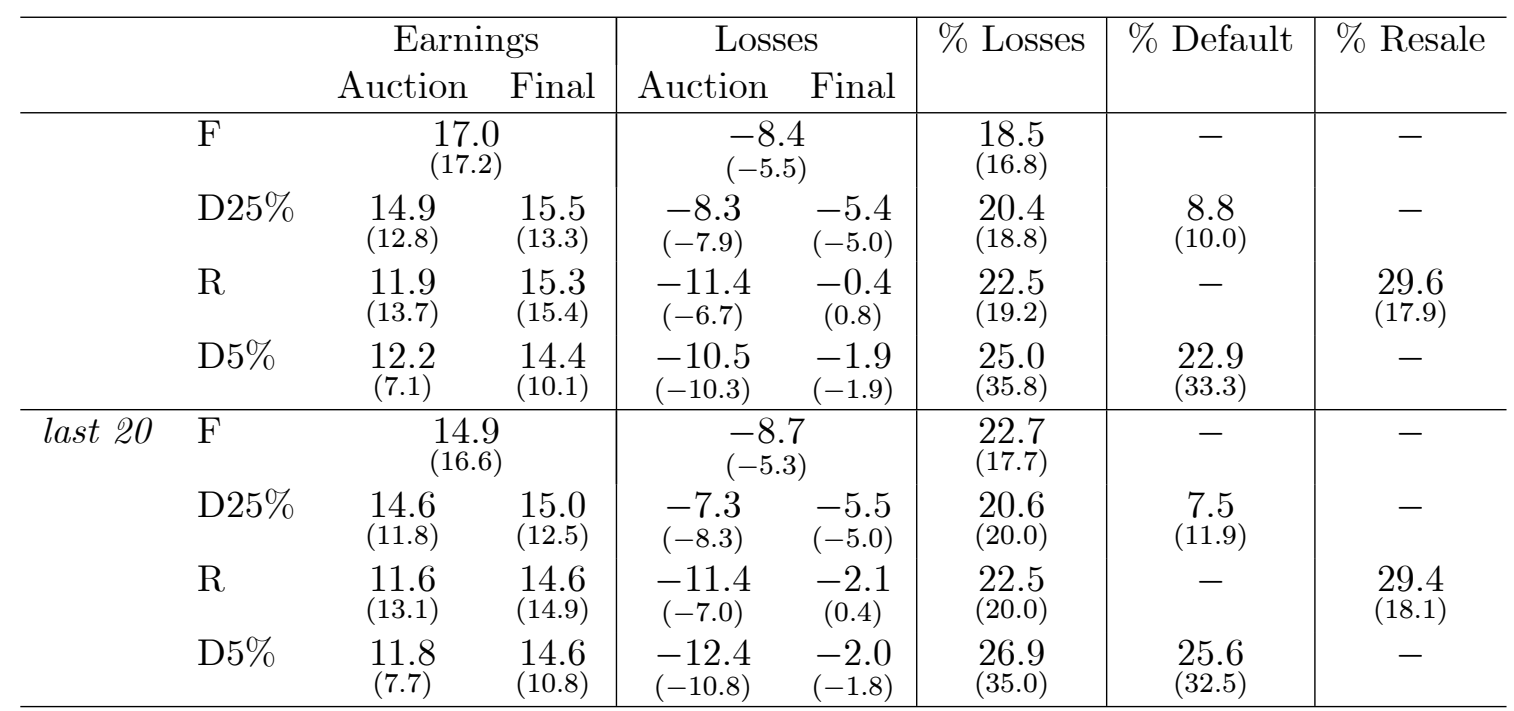

Table 4.2: Average observed earnings, and frequency of losses, default, and resale. Theoretical predictions in parentheses.

Table 4.2 summarizes bidders' earnings at the auction stage and final earnings which are adjusted for default and resale (columns 1 and 2). We also report auction and final average losses (i.e., earnings conditional on a bidder paying more than his value in the auction). The last three columns provide relative frequencies of auctions ending with bidder losses, default, and resale (by the winner to the highest-value bidder). We include comparisons to the theoretical predictions, based on the realized final draws from the experiment (rather than expectation), to evaluate the relative performance of theoretical behavior given the realized values. ${ }^{18}$

Higher auction prices in the $\mathrm{R}$ and D5\% treatments resulted in lower auction earnings for bidders, but resale and default helped raise final earnings by limiting losses. With full liability, bidders obtain higher average final earnings; but when the data is restricted to the last 20 periods, bidders are similarly well-off in all treatments, with average earnings around 15. After

\footnotetext{
${ }^{18}$ Although the equilibrium bidding strategy does not lead to losses in expectation, a bidder may still suffer losses for particular value realizations.
} 
the auction, bidder losses were reduced by all limited liability rules, with the strongest effect in the $\mathrm{R}$ and $\mathrm{D} 5 \%$ treatments.

Losses at the auction stage and default were most common in the low penalty (D5\%) treatment, which is expected since bidding is most aggressive in this treatment. The full liability (F) treatment results in the lowest frequency of losses, as predicted. Restricting the data to the last 20 periods, however, shows that bidders were least likely to make losses in the D25\% treatment. Resale markets opened in approximately $29 \%$ of auctions, which is 11 percentage points higher than the theoretical prediction. The resale market was not only used to mitigate losses; out of the 71 resale events, in 32 cases $(45 \%)$ the winning bidder was not making losses in the auction.

\begin{tabular}{|c|c|c|c|c|c|}
\hline & \multicolumn{2}{|c|}{ Auction Efficiency } & \multirow{2}{*}{$\begin{array}{c}\text { Final } \\
\text { Efficiency }\end{array}$} & \multirow{2}{*}{$\begin{array}{l}\text { Random } \\
\text { Efficiency }\end{array}$} \\
\hline & & pre-lottery & post-lottery & & \\
\hline & $\mathrm{F}$ & $\begin{array}{l}.94 \\
(1)\end{array}$ & $\begin{array}{c}.92 \\
(.96)\end{array}$ & $\begin{array}{c}.92 \\
(.96)\end{array}$ & .75 \\
\hline & D25\% & $\begin{array}{r}.92 \\
(1)\end{array}$ & $\begin{array}{r}.91 \\
(.96)\end{array}$ & $\begin{array}{l}.87 \\
(.88)\end{array}$ & .74 \\
\hline & $\mathrm{R}$ & $\begin{array}{l}.93 \\
(1)\end{array}$ & $\begin{array}{r}.92 \\
(.95)\end{array}$ & $\begin{array}{l}1 \\
(1)\end{array}$ & .75 \\
\hline & $\mathrm{D} 5 \%$ & $\begin{array}{l}.94 \\
(1)\end{array}$ & $\begin{array}{r}.92 \\
(.94)\end{array}$ & $\begin{array}{r}.74 \\
(.67)\end{array}$ & .75 \\
\hline \multirow[t]{4}{*}{ last 20} & $\mathrm{~F}$ & $\begin{array}{l}.95 \\
(1)\end{array}$ & $\begin{array}{c}.92 \\
(.95)\end{array}$ & $\begin{array}{c}.92 \\
(.95)\end{array}$ & .75 \\
\hline & D25\% & $\begin{array}{l}.93 \\
(1)\end{array}$ & $\begin{array}{r}.92 \\
(.95)\end{array}$ & $\begin{array}{c}.88 \\
(.86)\end{array}$ & .73 \\
\hline & $\mathrm{R}$ & $\begin{array}{l}.94 \\
(1)\end{array}$ & $\begin{array}{r}.93 \\
(.95)\end{array}$ & $\begin{array}{c}1 \\
(1)\end{array}$ & .74 \\
\hline & D $5 \%$ & $\begin{array}{l}.94 \\
(1)\end{array}$ & $\begin{array}{r}.93 \\
(.94) \\
\end{array}$ & $\begin{array}{r}.72 \\
(.67)\end{array}$ & .75 \\
\hline
\end{tabular}

Table 4.3: Average observed efficiency. Theoretical predictions in parentheses.

Table 4.3 summarizes auction efficiency and how (final) efficiency changes after the resolution of value uncertainty, as well as after resale and default when relevant. Theoretical predictions are based on signal draws for pre-lottery efficiency and realized final values for post-lottery and final efficiency. The random efficiency measures in the last two columns results from allocating the item to each of the two bidders with equal probability.

The uncertainty in final value creates two forms of auction efficiency. The pre-lottery efficiency is defined as the ratio between the signal of the auction winner and the highest signal of a bidders. In theory, this should be 1 in all treatments because bid functions are symmetric and increasing in private signals. The observed pre-lottery auction efficiency, while lower than 1 , is relatively high, with no notable difference across treatments. The post-lottery auction efficiency, calculated after the resolution of value uncertainty, is defined as the ratio between the value of the winner and the highest realized value. In all treatments, this is slightly lower than pre-lottery efficiency.

Because of default or resale, final allocative efficiency may differ from auction efficiency. Notice that resale generates a final efficiency of 1 as the item is transferred to the bidder with the highest realized value, while default generates a final efficiency of 0 since the item is returned 
to the seller. Final efficiency is lower in the D5\% and D25\% treatments, as bidders often exercised the default option, especially with a low penalty option.

Random efficiency is defined as the average of the two bidders' signals divided by the maximum signal. The auction always outperforms a random allocation in terms of efficiency. The limited liability environment, however, can negatively impact efficiency. In fact, final efficiency with a low default penalty (D5\%) is lower than with a random allocation, because of the very high default rates.

\subsection{Bidding Behavior}

Figure 4.1 provides a scatterplot of observed bids and private signal draws. ${ }^{19}$ The experiment implemented a between subjects design for the limited liability treatments and a within subjects design for the comparison of bidding behavior to the full liability baseline, so the graphs separate the full liability data by the limited liability treatment in which a subject participated. Each graph also includes the upper and lower bounds of the final use value $\left(x_{i}\right.$ and $\left.x_{i}+20\right)$, regression lines (dashed) for observed bids, and theoretical bid functions (solid).

Following the average bid patterns observed in table 4.1, bids appear higher with limited liability through resale (R) or with a low default penalty (D5\%) than under full liability (F). Contrasting the regression line with the theoretical prediction, it is evident that observed bids are less aggressive than predicted in both default treatments. In the $\mathrm{R}$ and $\mathrm{F}$ treatments, regression lines are above prediction for lower signals; while observed bids are at or below the prediction for higher signals.

Although bids should lie between the signal and the upper bound of the final use value in all treatments, we do observe bids outside of these bounds. ${ }^{20}$ Bids above the upper bound appear most frequently in the $\mathrm{R}$ and $\mathrm{D} 5 \%$ treatments, while bids below the lower bound appear more frequently in the $\mathrm{F}$ and D25\% treatments. ${ }^{21}$ In the analysis that follows, we report results based on all observations. In the appendix, we also present results excluding bids outside the bounds.

For a general view of treatment differences in bidding, we conduct power analysis on subsession averages for bids. The strongest analysis lies in the comparison of the $\mathrm{F}$ treatments to the limited liability treatments, due to the within subjects design. Comparing $\mathrm{F}$ versus $\mathrm{R}$ (using only the subset of $F(R)$ means), subsession averages of 35.2 for $F(R)$ and 38.1 for $R$ are significantly different $(p=0.01)$, with an estimated power of $98 \% .{ }^{22}$ Subsession averages of 35.5 for $\mathrm{F}(\mathrm{D} 5 \%)$ and 38.6 for D5\% are also significantly different $(p=0.03)$, and the power of this

\footnotetext{
${ }^{19}$ To improve readability, we only plot bids placed in rounds $3,8,13,16,23$, and 26.

${ }^{20}$ In the resale treatment, bidding above the upper bound might be due to speculation (bidding aggressively to win the item and resell). However, this cannot explain overbidding in the default and full liability treatments. The observed overbidding is similar to behavior in sealed-bid second price auctions with known valuations (Kagel et al., 1987; Cooper and Hang, 2008). This form of overbidding is different from the one observed in first price auction because of risk aversion (Cox et al., 1988).

${ }^{21}$ Bidders choosing to bid below the lower bound of the lottery was also observed by Katok and Salmon (2009) in a similar experimental design under full liability rules.

${ }^{22}$ The estimated mean effect under $\mathrm{R}$ for a test with $80 \%$ power and $\alpha=0.05$ is 37.12 .
} 

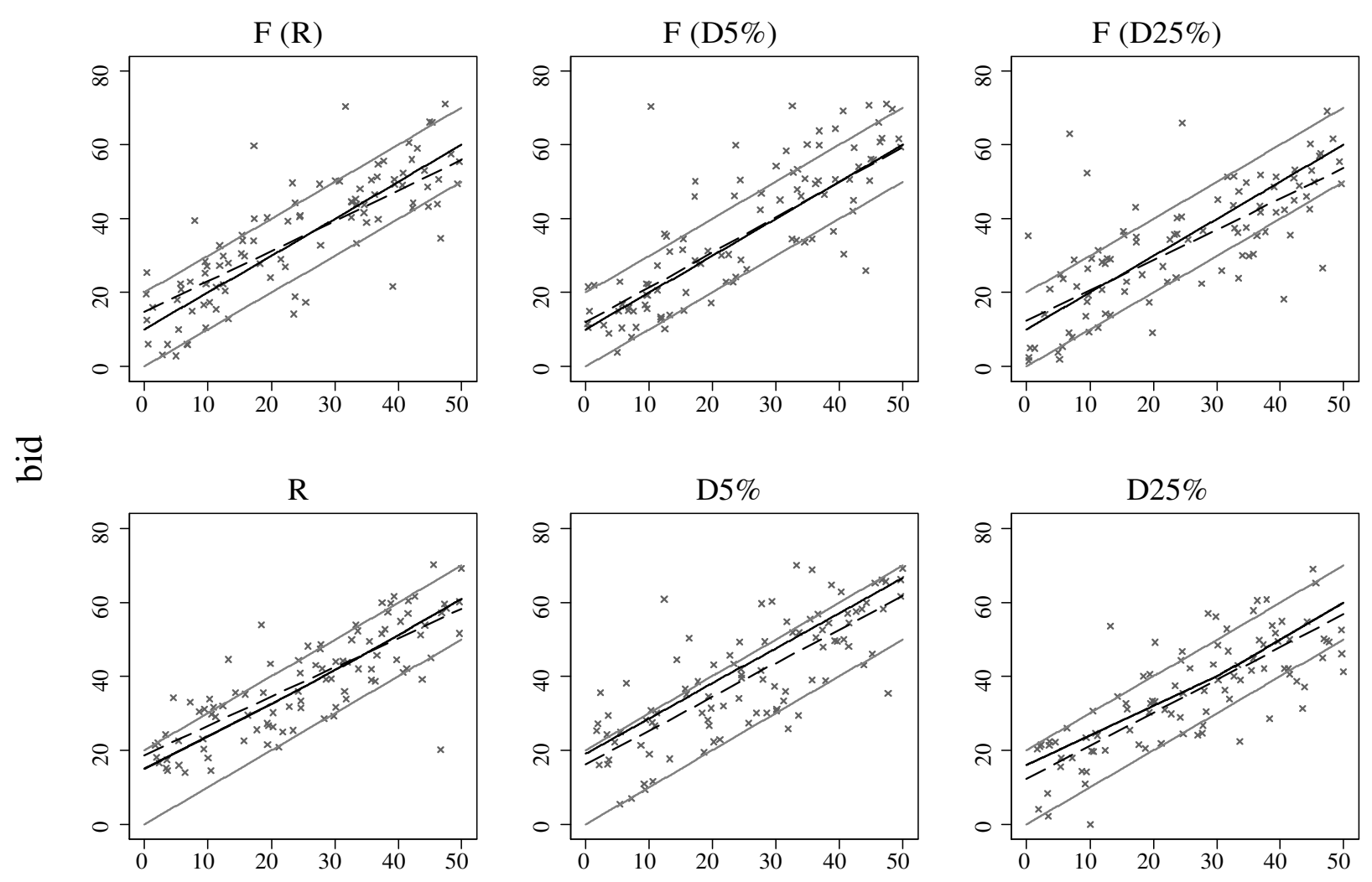

$\mathrm{X}$

Figure 4.1: Scatterplot of observed bids and signal $x_{i}$. The upper $\left(x_{i}+20\right)$ and lower bounds $\left(x_{i}\right)$ for use values are in light gray. Dashed black lines are regression lines for the observed data, and solid black lines represent the theoretical bid functions.

test is $78 \%{ }^{23}$ In the comparison of $\mathrm{F}(\mathrm{D} 25 \%)$ and D25\%, the subsession averages of 32.9 and 34.2 are not significantly different $(p=0.27)$. The estimated effect size in the D25\% treatment for a power level of $80 \%, \alpha=0.05$, and given the mean bid of 32.9 in the $\mathrm{F}(\mathrm{D} 25 \%)$ treatment is 36.9 , which is above what we observe.

Examining subsession average bids across limited liability treatments, there is a notable difference between the $\mathrm{R}$ and D25\% treatments with subsession averages of 38.1 and 34.2, which are significantly different from each other $(p=0.06)$. However the power of this test is only $50 \%$ given the between subjects nature of the data. ${ }^{24}$ Similarly, we observe differences between the D5\% and D25\% treatments (averages of 38.6 and $34.2, p=0.10$ ), but the power is $37 \%$ due to a higher difference in standard deviations. ${ }^{25}$

\footnotetext{
${ }^{23}$ The estimated mean effect under D5\% for a test with $80 \%$ power and $\alpha=0.05$ is 38.7 .

${ }^{24}$ To reach a power level of $80 \%$, given $\alpha=0.05$, we would need 14 independent observations (the current data has 8$)$.

${ }^{25}$ Despite having a similar difference in means to the R/D25\% comparison, the difference in standard deviations
} 
To test the relationship between theoretical and actual bids, we analyze regressions with the observed bid as the dependent variable and the predicted theoretical bid as the independent variable for each treatment (see table A.1 in the appendix). When observed bids match the theoretical predictions, the coefficient on the theoretical bid should equal to 1 . In the $\mathrm{F}$ and $\mathrm{R}$ treatments, post-estimation tests did not reject the hypothesis that the coefficient on the theoretical bid is 1 ( $p \geq 0.13$ ), demonstrating adherence to the theory. In the D5\% treatment, this coefficient is .91 and significantly different from $1(p=0.02)$, indicating that bidding with a low default penalty is less aggressive than predicted. In the $\mathrm{D} 25 \%$ treatment, we also find evidence that observed bids are lower than predicted with a coefficient of .94, however the p-value resulting from the coefficient test for difference from 1 is only marginally significant $(p=0.09) .{ }^{26}$

\begin{tabular}{|c|c|c|c|c|c|c|}
\hline & (1) & $(2)$ & (3) & $(4)$ & $(5)$ & $(6)$ \\
\hline & all & last 20 & $x_{i}<30$ & $x_{i}<30 \&$ last 20 & $x_{i}>30$ & $x_{i}>30 \&$ last 20 \\
\hline \multirow[t]{2}{*}{$x_{i}$} & $0.886^{* * *}$ & $0.934^{* * *}$ & $0.942^{* * *}$ & $0.972^{* * *}$ & $0.689^{* * *}$ & $0.760^{* * *}$ \\
\hline & $(0.0215)$ & $(0.0217)$ & $(0.0306)$ & $(0.0274)$ & $(0.0427)$ & $(0.0720)$ \\
\hline \multirow[t]{2}{*}{$\mathrm{R}$} & $3.153^{* * *}$ & 1.330 & $3.178^{* * *}$ & $1.137^{*}$ & $3.182^{* * *}$ & 1.699 \\
\hline & $(0.393)$ & $(0.769)$ & $(0.479)$ & $(0.592)$ & $(0.949)$ & $(1.086)$ \\
\hline \multirow[t]{2}{*}{ D5\% } & $3.342^{* * *}$ & $3.202^{* * *}$ & $3.854^{* * *}$ & $3.828^{* * *}$ & $2.598 * * *$ & $2.238^{* * *}$ \\
\hline & $(0.420)$ & $(0.341)$ & $(0.608)$ & $(0.378)$ & $(0.450)$ & $(0.686)$ \\
\hline \multirow[t]{2}{*}{$\mathrm{D} 25 \%$} & $1.582^{* *}$ & 0.655 & 1.007 & 0.176 & $2.475^{*}$ & 1.521 \\
\hline & $(0.701)$ & $(0.958)$ & $(0.691)$ & $(0.845)$ & (1.146) & (1.158) \\
\hline \multirow[t]{2}{*}{ Constant } & $12.51^{* * *}$ & $13.21^{* * *}$ & $11.92^{* * *}$ & $12.76^{* * *}$ & $20.05^{* * *}$ & $20.04^{* * *}$ \\
\hline & $(0.574)$ & $(0.614)$ & $(0.544)$ & $(0.436)$ & $(1.708)$ & $(2.892)$ \\
\hline Observations & 2,880 & 1,920 & 1,719 & 1,191 & 1,161 & 729 \\
\hline R-squared & 0.692 & 0.766 & 0.494 & 0.551 & 0.189 & 0.301 \\
\hline Clusters & 12 & 12 & 12 & 12 & 12 & 12 \\
\hline
\end{tabular}

Table 4.4: Fixed effects regressions with bid as the dependent variable. Standard errors clustered at the subsession level.

To examine the treatment effects on bidding behavior, table 4.4 presents fixed effects regression results with bid as the dependent variable. Models 1 and 2 examine basic treatment effects, while models 3-6 account for differences based on low and high signal draws. Models 1, 3, and 5 use data from all periods, while models $2,4,6$ restrict the data to the last 20 periods. In all specifications, the full liability treatment is the baseline and all models include the private signal draw $x_{i}$ and treatment dummies.

The positive significant coefficients on all treatment dummies in model 1 indicate that bids are significantly higher in all limited liability treatments than in the full liability baseline, pro-

between D5\%/D25\% was higher. Hence, to reach a power level of $80 \%$, given $\alpha=0.05$, we would need 20 independent observations (the current data has 8).

${ }^{26}$ Omitting observations where bidders bid below their signal or above the upper bound for final value, we obtain similar qualitative results except for the $\mathrm{R}$ treatment, where a test that the coefficient on theory bid is equal to 1 is rejected (coefficient $0.97, p=0.05$ ), so observed bids are lower than predicted. 
viding support for the theoretical predictions. Post-estimation tests between the limited liability coefficients also demonstrate significant differences between the D25\% and both the D5\% $(p=0.05)$ and $\mathrm{R}$ treatments $(p=0.07)$, supporting theoretical results 1 and 3. No significant differences are found between the $\mathrm{R}$ and D5\% treatments $(p=0.74)$, in contrast to the prediction of theoretical result 4 .

In models 3 and 5, the significant effect of the D25\% treatment is mitigated, only reaching marginal significance for high signals. Coefficient tests between liability treatments in model 3 (low signals) demonstrate results similar to model 1: significant differences between the D25\% and both the $\mathrm{R}$ and $\mathrm{D} 5 \%$ treatments ( $p=0.02$ and $p=0.01$, respectively), and no significant differences between the $\mathrm{R}$ and $\mathrm{D} 5 \%$ treatments $(p=0.39)$. In model 5 , differences between the limited liability conditions are reduced as coefficient tests demonstrate no significant difference between treatments $(p \geq 0.58)$, although bidding is still higher than with full liability.

In model 2,4 , and 6 , the positive significant coefficient on the D5\% treatment across all specifications restricted to the last 20 periods indicate that bids are significantly higher than in the full liability baseline, while no significant differences are found for the R and D25\% treatments. Notice, however, that this is not necessarily due to a reduction in aggressive bidding in these treatments, because the higher constant in models 2 and 4 indicates higher average bids than in the full liability treatment. This mirrors what was observed in the average bids summary in table 4.1. Consequently, the increase in bids in the baseline F makes it less likely to observe differences, unless bids are also increasing in the limited liability treatments.

Coefficient tests between the limited liability treatments in model 2 demonstrate significant differences between the D5\% and both $\mathrm{R}$ and D25\% treatments $(p=0.04$ and $p=0.02$, respectively), while no significant difference emerges between the $\mathrm{R}$ and $\mathrm{D} 25 \%$ treatments $(p=0.59)$. Results are similar for coefficient tests in model $4 .{ }^{27}$ In model 6 , coefficient tests show no significance difference between the limited liability treatments $(p \geq 0.60)$, confirming that for higher signals treatment differences are minimal in later periods. ${ }^{28}$

Empirical Result 1: Bidding with limited liability is more aggressive than with full liability $(F)$, especially in the low default penalty (D5\%) and resale $(R)$ treatments. This difference decreases over time, except in the low default penalty (D5\%) treatment.

\footnotetext{
${ }^{27}$ Coefficient tests between the $\mathrm{D} 5 \%$ and $\mathrm{R}$ or $\mathrm{D} 5 \%$ and $\mathrm{D} 25 \%$ report $p<0.01$, while the test between $\mathrm{R}$ and D25\% reports $p=0.37$.

${ }^{28}$ We report the same set of regressions with observations where bidders bid below their signal or above the upper bound for final value omitted in table A.2 in the appendix. Similar to the regressions testing the theoretical bid, the discussed results qualitatively hold, with a notable difference in the $\mathrm{R}$ treatment. In this case, bidding more aggressively than the $\mathrm{F}$ treatment is then only marginally significant. Of course, with resale, speculation is a possible strategy, so bidding above bounds can be explained by this and so the restricted results are not as informative since overbidding is not necessarily due to mistakes in bidding.
} 


\subsection{Outcomes}

In this section, we formally analyze outcomes including auction prices, sellers' revenue, efficiency, and buyers' earnings.

Table 4.5 presents pooled OLS regressions on auction price, final revenue, and final efficiency. The first two models have the auction price as the dependent variable; model 1 includes data from all periods and model 2 is the restricted to the last 20 periods. The variables $X_{(1)}$ and $X_{(2)}$ represent the highest and second highest signal draws in each auction group, respectively. We also include variables for the risk profile of the participants in an auction group: max Safe is the highest number of safe choices and min Safe is the minimum number of safe choices made by a participant in the Holt and Laury (2002) risk preferences procedure. ${ }^{29}$

\begin{tabular}{|c|c|c|c|c|c|c|}
\hline & (1) & $(2)$ & (3) & (4) & $(5)$ & (6) \\
\hline & \multicolumn{2}{|c|}{ Auction Price } & \multicolumn{2}{|c|}{ Final Revenue } & \multicolumn{2}{|c|}{ Final Efficiency } \\
\hline & & last 20 & & last 20 & & last 20 \\
\hline \multirow[t]{2}{*}{$X_{(1)}$} & $0.129^{* * *}$ & $0.106^{* * *}$ & $0.186^{* * *}$ & $0.170^{* * *}$ & $0.00590^{* * *}$ & $0.00611^{* * *}$ \\
\hline & $(0.0194)$ & $(0.0202)$ & $(0.0235)$ & $(0.0269)$ & $(0.000915)$ & $(0.000795)$ \\
\hline \multirow[t]{2}{*}{$X_{(2)}$} & $0.766^{* * *}$ & $0.888^{* * *}$ & $0.655^{* * *}$ & $0.716^{* * *}$ & $-0.00469^{* * *}$ & $-0.00628^{* * *}$ \\
\hline & $(0.0189)$ & $(0.0286)$ & $(0.0380)$ & $(0.0645)$ & (0.000997) & $(0.00138)$ \\
\hline \multirow[t]{2}{*}{$\mathrm{R}$} & $4.623^{* * *}$ & $3.365^{* * *}$ & $4.532^{* * *}$ & $3.112^{* * *}$ & $0.0751^{* * *}$ & $0.0741^{* * *}$ \\
\hline & $(0.612)$ & $(0.872)$ & $(0.556)$ & $(0.797)$ & $(0.00732)$ & $(0.00764)$ \\
\hline \multirow[t]{2}{*}{$\mathrm{D} 5 \%$} & $3.748^{* * *}$ & $3.564^{* * *}$ & $-4.508^{* * *}$ & $-6.466^{* * *}$ & $-0.177^{* * *}$ & $-0.195^{* * *}$ \\
\hline & $(0.741)$ & $(0.828)$ & $(0.891)$ & (1.632) & $(0.0213)$ & $(0.0325)$ \\
\hline \multirow[t]{2}{*}{$\mathrm{D} 25 \%$} & 0.206 & -1.134 & $-1.654^{* *}$ & $-2.711^{*}$ & $-0.0491^{* *}$ & -0.0293 \\
\hline & $(0.705)$ & $(0.912)$ & $(0.685)$ & (1.298) & $(0.0209)$ & $(0.0187)$ \\
\hline \multirow[t]{2}{*}{$\max$ Safe } & $-0.461^{*}$ & $-0.707^{* *}$ & $-0.524^{*}$ & $-0.610^{* *}$ & -0.00571 & -0.00331 \\
\hline & $(0.243)$ & $(0.264)$ & $(0.261)$ & $(0.232)$ & $(0.00453)$ & $(0.00483)$ \\
\hline \multirow[t]{2}{*}{ min Safe } & 0.272 & 0.581 & 0.138 & 0.232 & -0.00298 & -0.0101 \\
\hline & $(0.466)$ & $(0.614)$ & $(0.337)$ & $(0.490)$ & $(0.00640)$ & $(0.00920)$ \\
\hline \multirow[t]{2}{*}{ Constant } & $9.852^{* * *}$ & $10.44^{* * *}$ & $10.76^{* * *}$ & $12.02^{* * *}$ & $0.851^{* * *}$ & $0.885^{* * *}$ \\
\hline & $(2.707)$ & $(2.972)$ & $(2.350)$ & $(2.761)$ & $(0.0521)$ & $(0.0482)$ \\
\hline Observations & 1,440 & 960 & 1,440 & 960 & 1,440 & 960 \\
\hline R-squared & 0.546 & 0.624 & 0.457 & 0.492 & 0.167 & 0.190 \\
\hline Clusters & 12 & 12 & 12 & 12 & 12 & 12 \\
\hline
\end{tabular}

Table 4.5: Pooled OLS regressions with either auction price, final revenue, or final efficiency as the dependent variable. Standard errors clustered at the subsession level.

By theoretical results 1-4, the auction price should be highest in the D5\% treatment and lowest in the $\mathrm{F}$ treatment (and also in the D25\% treatment for higher signals). The results in table 4.5 partially support the theory. The significant coefficients on the $\mathrm{R}$ and $\mathrm{D} 5 \%$ treatment dummies and joint coefficient tests between the $\mathrm{R}$ and $\mathrm{D} 5 \%$ treatments $(p>0.212)$ provide

\footnotetext{
${ }^{29}$ We obtain similar qualitative results for treatment effects if we exclude these behavioral measures.
} 
evidence that auction prices are highest in the D5\% treatment, but also that they are equivalently high in the $\mathrm{R}$ treatment (in contrast to predictions). The second highest signal impacts the auction price more than the highest signal, which is expected in a second price auction where the highest losing bid sets the price.

Empirical Result 2: Auction prices are highest in the low default penalty (D5\%) and resale (R) treatments, and lowest in the high default penalty (D25\%) and full liability $(F)$ treatments.

Models 3 and 4 examine final revenue of the auction seller, which can differ from the auction price only in the default treatments. More aggressive bidding and lack of default in the resale treatment leads to the highest final revenue. While auction prices are high also in the D5\% treatment, the frequency of default significantly lowers revenue compared to the full liability treatment. Default also significantly lowers revenue in the D25\% default treatment, but the magnitude of this effect is smaller and, in later periods, is only significantly different from full liability at marginal levels. The data also provides a behavioral effect of risk aversion: the negative and significant coefficient on max Safe shows that groups with more risk averse bidders have lower prices, and this effect is strengthened over time.

Models 5 and 6 examine final efficiency, which takes into account default and resale. Final efficiency is 0 with default (since the buyer returns the item to the seller), is 1 with resale (since the item is transferred to the bidder with the highest final value), and is equivalent to auction efficiency otherwise. The positive significant coefficient on the resale treatment $(\mathrm{R})$ dummy and negative significant coefficient on the low default penalty (D5\%) dummy indicate that final efficiency is higher with resale and lower with a low default penalty than in the full liability baseline, as expected. Behavioral differences in bidding also impacted efficiency because increases in the second highest signal of a group reduces efficiency: the higher the signal of the bidder who should lose, the more likely the auction allocation is to be inefficient. ${ }^{30}$

Empirical Result 3: Final revenue and efficiency are highest in the resale treatment $(R)$ and lowest in the low default penalty treatment (D5\%). Final revenue and efficiency are lower in the high default penalty treatment (D25\%) than in the full liability treatment $(F)$, but this effect decreases over time.

Table 4.6 examines bidders' welfare and provides fixed effects regressions on bidders' final earnings, taking into account both resale and default. Models 1 and 2 have unconditional final earnings as the dependent variable, while models 3 and 4 only consider observations where bidders were making a loss at the conclusion of the auction (in order to analyze which limited liability treatment is most effective in mitigating losses).

\footnotetext{
${ }^{30}$ Table A.3 in the appendix reports the same set of regressions with restricted data that omit groups with at least one bidder who bid less than his signal or more than his highest final value. The results are qualitatively similar, but significance levels are reduced. Of course, this must be interpreted cautiously since the restriction eliminates a large number of group observations due to the strict rule of deleting any group where at least one bidder bid outside of bounds (regardless of whether the other bidder bid within bounds).
} 


\begin{tabular}{lcccc}
\hline & $(1)$ & $(2)$ & $(3)$ & $(4)$ \\
& \multicolumn{2}{c}{ Final Earnings } & \multicolumn{2}{c}{ Final Losses } \\
& & last 20 & & last 20 \\
\hline$x_{i}$ & $0.528^{* * *}$ & $0.508^{* * *}$ & -0.0523 & -0.0371 \\
& $(0.0445)$ & $(0.0367)$ & $(0.0476)$ & $(0.0224)$ \\
$\mathrm{R}$ & -0.440 & 0.280 & $8.280^{* *}$ & 5.141 \\
& $(0.894)$ & $(0.950)$ & $(2.713)$ & $(3.370)$ \\
D5\% & -1.189 & 0.0294 & $7.363^{* * *}$ & $7.501^{* * *}$ \\
& $(1.052)$ & $(1.636)$ & $(0.747)$ & $(0.992)$ \\
D25\% & $-2.639^{* *}$ & 0.433 & 3.168 & $4.309^{*}$ \\
& $(1.114)$ & $(1.713)$ & $(1.795)$ & $(2.107)$ \\
Constant & 0.170 & -0.746 & $-7.361^{* * *}$ & $-7.843^{* * *}$ \\
& $(1.264)$ & $(0.762)$ & $(0.927)$ & $(0.675)$ \\
\hline Observations & 1,440 & 960 & 296 & 221 \\
R-squared & 0.166 & 0.142 & 0.232 & 0.246 \\
Clusters & 12 & 12 & 12 & 12 \\
\hline \multicolumn{5}{c}{ Robust standard errors in parentheses } \\
& $* * * \mathrm{p}<0.01, * * \mathrm{p}<0.05, * \mathrm{p}<0.1$ &
\end{tabular}

Table 4.6: Fixed effects regressions with bidder final earnings as the dependent variable. Standard errors clustered at the subsession level.

In model 1, the negative coefficients on the D25\% treatment dummy indicates that bidders earned significantly less under the $25 \%$ default penalty than full liability $(\mathrm{F})$. For the R and D5\% treatments, earnings are not significantly different from the full liability baseline. Coefficient tests indicate that earnings are not statistically different between any of the limited liability treatments $(p \geq 0.15)$. In model 2 (the last 20 periods), bidders' earnings in the $\mathrm{R}, \mathrm{D} 5 \%$, or D25\% treatments are not significantly different from full liability and coefficient tests between limited liability treatments also indicate no differences $(p \geq 0.85)$. Models 3 and 4 provide evidence that the $\mathrm{R}$ and D5\% treatments reduce final losses, while the D25\% treatment does not significantly improve losses over full liability. Shifting to the last 20 periods (in model 4), the $\mathrm{D} 5 \%$ treatment is the only treatment that robustly mitigates losses. ${ }^{31}$

Empirical Result 4: Bidders' earnings are statistically equivalent across all treatments. Bidders' losses are lowest in the resale $(R)$ and low default penalty (D5\%) treatments, but this effect decreases over time for the resale $(R)$ treatment.

\section{Conclusion}

We study how different liability conditions affect bidder strategies in auctions with uncertain values, and consequently revenue, efficiency, and bidders' welfare. Evidence from an incentivized

\footnotetext{
${ }^{31}$ The same set of regressions where the data is omitted when a bidder bid below his signal or above the highest final value yield the same qualitative results (see table A.4 in the appendix). No differences are found in bidders' earnings between treatments.
} 
environment shows that bidders do respond to changes in liability rules, but the level of the response depends on the form and level of liability. Bidders are most aggressive when statutory liability requirements (i.e. default payments) are low, but they also respond aggressively to external market-based limited liability induced by the presence of a resale market. In contrast to predictions, bids under a high default penalty are not more aggressive than with full liability and are significantly lower than in the other limited liability environments.

Although a low default payment yields the most aggressive bidding, default limits the revenue collected by the seller to a fraction of the auction price. The highest revenue is achieved in the resale treatment, where more aggressive bidding leads to higher prices without default. Moreover, resale outperformed the other environments in terms of efficiency since it provides an opportunity to correct an inefficient auction allocation. From the bidder's perspective, resale and the low default penalty are most effective in mitigating losses.

While we provide a first empirical look into bidders' response across liability requirements, there are a number of key differences between the environments tested and the field that should be taken into account when interpreting our results. First, we assumed an automated default choice and did not consider future penalties in reputation or monetary payments. In the field, bidders may be unwilling to exercise a default option for reputation reasons, so our results are more informative for auctions where repeated interaction is unlikely. Second, the resale market was also automated and took place immediately after the auction if gains from trade existed. While resale does not bear the same stigma as default, market frictions like incomplete information may limit the efficiency and the probability of resale in the field, which would lower the limited liability incentives provided by resale.

In sum, the level of liability (high or low) and type of limited liability (statutory or through resale) are both critical factors influencing the behavioral response of bidders. Our results suggest that both sellers and bidders may prefer to have post-auction resale as a mechanism to limit losses of bidders who are uncertain about their values, while simultaneously increasing revenue. In all cases, liability requirements must be carefully considered when designing auction markets, as they will affect the revenue and efficiency achieved. 


\section{References}

[1] Bernard, J. (2006) "Finding and retaining the dominant strategy: The second-price, English and 'sealed offer' English auctions," Journal of Economic Behavior \&3 Organization 60(4), 553-561.

[2] Botrd, S. (2007) "Bidding into the Red: A Model of Post-Auction Bankruptcy," Journal of Finance, 62(6), 2695-2723.

[3] Burguet, R., J. Ganuza, and E. Hauk (2012) "Limited liability and mechanism design in procurement," Games and Economic Behavior 76(1), 15-15.

[4] Calzolari, G., and A. Pavan (2006) "Monopoly with Resale." RAND Journal of Economics, 73(2), 362-375.

[5] Cooper, D., and H. Fang (2008) "Understanding Overbidding in Second Price Auctions: An Experimental Study," Economic Journal, 118 (532), 1572 - 1595.

[6] Cox, J., V. Smith, and J. Walker (1988) "Theory and Individual Behavior of First-Price Auctions," Journal of Risk and Uncertainty, 1(1), 61-99.

[7] Fischbacher, U. (2007) "Z-Tree: Zurich Toolbox For Readymade Economic Experiments," Experimental Economics 10 (2), 171-178.

[8] Greiner, B. (2004) "The Online Recruitment System ORSEE 2.0 - A Guide for the Organization of Experiments in Economics." University of Cologne, mimeo.

[9] Haile, P. (2001) "Auctions with resale markets: an application to US forest service timber sales," American Economic Review, 91(3), 399-427.

[10] Haile, P. (2003) "Auctions with Private Uncertainty and Resale Opportunities," Journal of Economic Theory 108, 72-110.

[11] Harstad, R., and M. Rothkopf (1995) "Withdrawable bids as winner's curse insurance," Operations Research, 43(6), 983-994.

[12] Holt, C., and S. Laury (2002) "Risk Aversion and Incentive Effects," American Economic Review, 92(5), 1644-1655.

[13] Kagel, J., and D. Levin. (1986) "The Winner's Curse and Public Information in Common Value Auctions," American Economic Review, 76, 894-920.

[14] Kagel, J., and D. Levin (1991) "The Winner's Curse and Public Information in Common Value Auctions: Reply," American Economic Review, 81, 362-369.

[15] Kagel, J., R. Harstad, and D. Levin (1987), "Information Impact and Allocation Rules in Auctions with Affiliated Private Values: A Laboratory Study," Econometrica, $55,1275-1304$.

[16] Katok, E., and T. Salmon (2009) "Response of Risky Choice to Variance Reduction," mimeo. 
[17] Klemperer, P. (2002). "What Really Matters in Auction Design." Journal of Economic Perspectives, 16(1), 169-189.

[18] McMillan, J. (1994) "Selling Spectrum Rights." Journal of Economic Perspectives, 8(3), 145-162.

[19] Onderstal, S., and A. Van der Veen (2011) "Keeping out Trojan horses: Auctions and bankruptcy in the laboratory," mimeo.

[20] Parlane, S. (2003) "Procurement contracts under limited liability," The Economic and Social Review 34(1), 1-21.

[21] Pagnozzi, M. (2007a) "Bidding to Lose? Auctions with Resale," RAND Journal of Economics, 38(4), 1090-1112.

[22] Pagnozzi, M. (2007b) "Sorry Winners," Review of Industrial Organization, 30, 203-225.

[23] Pagnozzi, M., and K. Saral (2017) "Demand Reduction in Multi-object Auctions with Resale: An Experimental Analysis." Economic Journal, 127(607), 2702-2729.

[24] Roelofs, M. (2002) "Common Value Auctions with Default: An Experimental Approach," Experimental Economics, 5(3), 233-252.

[25] Waehrer, K. (1995) "A Model of Auction Contracts with Liquidated Damages," Journal of Economic Theory, 67(2), 531-555.

[26] Zheng, C. (2001) "High Bids and Broke Winners," Journal of Economic Theory, 100(1), 129-171. 


\section{A. Appendix}

\section{A.1. Equilibrium Bidding Functions.}

Consider first Limited Liability through Resale. In this case,

$$
\begin{aligned}
\operatorname{Pr}[\text { resale } \mid i \text { wins }] & =\operatorname{Pr}\left[\varepsilon_{j}=\bar{\varepsilon}\right] \times \operatorname{Pr}\left[\varepsilon_{i}=0\right] \times \operatorname{Pr}\left[x_{i}-x_{j}<\bar{\varepsilon} \mid x_{i}>x_{j}\right] \\
& =\min \left\{\frac{\bar{\varepsilon}}{4 x_{i}} ; \frac{1}{4}\right\} .
\end{aligned}
$$

Moreover, $\mathbb{E}\left[x_{j} \mid i\right.$ wins $]=\frac{x_{i}}{2}$ and the expected resale price conditional on bidder $i$ winning and reselling is

$$
\begin{aligned}
\mathbb{E}[\text { resale price } \mid i \text { wins and resells }] & =\mathbb{E}\left[v_{j} \mid x_{i}>x_{j} \text { and } v_{j}>v_{i}\right] \\
& =\max \left\{\frac{x_{i}}{2}+\bar{\varepsilon} ; x_{i}+\frac{\bar{\varepsilon}}{2}\right\} .
\end{aligned}
$$

Finally, notice that

$$
\begin{aligned}
\mathbb{E}\left[\varepsilon_{i} \mid x_{i}>x_{j}, x_{i}<\bar{\varepsilon} \text { and } v_{i}>v_{j}\right] & =\mathbb{E}\left[\varepsilon_{i} \mid \varepsilon_{i} \geq \varepsilon_{j}\right] \\
& =0 \times \frac{1}{3}+\bar{\varepsilon} \times \frac{2}{3}
\end{aligned}
$$

and

$$
\begin{aligned}
\mathbb{E}\left[\varepsilon_{i} \mid x_{i}>x_{j}, x_{i}>\bar{\varepsilon} \text { and } v_{i}>v_{j}\right] & =\frac{\operatorname{Pr}\left[x_{j}<x_{i}-\bar{\varepsilon}\right]}{\operatorname{Pr}\left[v_{i}<v_{j} \mid x_{i}>x_{j} \text { and } x_{i}>\bar{\varepsilon}\right]} \mathbb{E}\left[\varepsilon_{i}\right]+ \\
& \frac{\operatorname{Pr}\left[x_{i}-\bar{\varepsilon}<x_{j}<x_{i} \text { and } v_{i}>v_{j}\right]}{\operatorname{Pr}\left[v_{i}<v_{j} \mid x_{i}>x_{j} \text { and } x_{i}>\bar{\varepsilon}\right]} \mathbb{E}\left[\varepsilon_{i} \mid \varepsilon_{i} \geq \varepsilon_{j}\right] \\
& =\frac{4 x_{i}-4 \bar{\varepsilon} \bar{\varepsilon}}{4 x_{i}-\bar{\varepsilon}} \frac{\bar{\varepsilon}}{2}+\frac{\bar{\varepsilon}}{4 x_{i}-\bar{\varepsilon}} 2 \bar{\varepsilon}=\frac{2 x_{i} \bar{\varepsilon}}{4 x_{i}-\bar{\varepsilon}} .
\end{aligned}
$$

Therefore, when $x_{i}<20$,

$$
\begin{aligned}
\mathbb{E}\left[\pi_{i} \mid i \text { wins }\right] & =\operatorname{Pr}[\text { no resale } \mid i \text { wins }] \times \mathbb{E}\left[v_{i} \mid i \text { wins and does not resell }\right]+ \\
& \operatorname{Pr}[\text { resale } \mid i \text { wins }] \times \mathbb{E}[\text { resale price } \mid i \text { wins and resells }] \\
& =\frac{3}{4} \times\left(x_{i}+\frac{2}{3} \bar{\varepsilon}\right)+\frac{1}{4} \times\left(\frac{x_{i}}{2}+\bar{\varepsilon}\right) \\
& =\frac{7}{8} x_{i}+\frac{3}{4} \bar{\varepsilon} .
\end{aligned}
$$


By contrast, when $x_{i}>20$,

$$
\begin{aligned}
\mathbb{E}\left[\pi_{i} \mid i \text { wins }\right] & =\left(1-\frac{\bar{\varepsilon}}{4 x_{i}}\right) \times\left(x_{i}+\frac{2 x_{i} \bar{\varepsilon}}{4 x_{i}-\bar{\varepsilon}}\right)+\frac{\bar{\varepsilon}}{4 x_{i}} \times\left(x_{i}+\frac{\bar{\varepsilon}}{2}\right) \\
& =x_{i}+\frac{\bar{\varepsilon}}{2}+\frac{\bar{\varepsilon}^{2}}{8 x_{i}} .
\end{aligned}
$$

This yields the equilibrium bidding function (2.2).

Consider now Limited Liability through Default. Notice that a bidder never bids more than $x_{i}+\bar{\varepsilon}$, his highest possible use value. When $\varepsilon_{i}=\bar{\varepsilon}$, the winning bidder never defaults (since a bidder never pays an auction price higher than $x_{i}+\bar{\varepsilon}$ and hence his profit from not defaulting is strictly positive when $\varepsilon_{i}=\bar{\varepsilon}$ ). When $\varepsilon_{i}=0$, the winning bidder defaults if

$$
x_{i}-p<-\alpha p \quad \Leftrightarrow \quad p>\frac{x_{i}}{1-\alpha} .
$$

Suppose that bidder $i$ defaults if $\varepsilon_{i}=0$. Since losing the auction yields a profit of 0 , in a second-price auction the bidder bids a price $p^{*}$ such that his expected payoff from winning the auction is equal to zero - i.e.,

$$
\begin{gathered}
\operatorname{Pr}\left[\varepsilon_{i}=\bar{\varepsilon}\right] \times\left(x_{i}+\bar{\varepsilon}-p^{*}\right)+\operatorname{Pr}\left[\varepsilon_{i}=0\right] \times\left(-\alpha p^{*}\right)=0 \\
\Leftrightarrow \quad \frac{x_{i}+\bar{\varepsilon}-(1+\alpha) p^{*}}{2}=0 \quad \Leftrightarrow \quad p^{*}=\frac{x_{i}+\bar{\varepsilon}}{1+\alpha} .
\end{gathered}
$$

Of course, bidder $i$ never defaults if his profit from not defaulting is greater than the default penalty, when he wins the auction at price $p^{*}$ and $\varepsilon_{i}=0-$ i.e., when

$$
x_{i}-\frac{x_{i}+\bar{\varepsilon}}{1+\alpha}>-\alpha \frac{x_{i}+\bar{\varepsilon}}{1+\alpha} \Leftrightarrow x_{i}>x^{*} \equiv \frac{(1-\alpha) \bar{\varepsilon}}{2 \alpha} .
$$

(In other words, $p^{*}<\frac{x_{i}}{1-\alpha}$ if $x_{i}>x^{*}$, so that bidder $i$ has no incentive to bid a price that makes default attractive.) In this case, bidder $i$ bids $x_{i}+\frac{\bar{\varepsilon}}{2}$, the price at which his expected profit is equal to zero when he always pay the auction price.

Therefore, the equilibrium bidding function with default is (2.3).

\section{A.2. Additional Regressions}




\begin{tabular}{lcccc}
\hline & $(1)$ & $(2)$ & $(3)$ & $(4)$ \\
& $\mathrm{F}$ & $\mathrm{R}$ & $\mathrm{D} 5 \%$ & $\mathrm{D} 25 \%$ \\
\hline Theory bid, $b_{i}$ & $0.972^{* * *}$ & $1.010^{* * *}$ & $0.914^{* * *}$ & $0.947^{* * *}$ \\
& $(0.0169)$ & $(0.0194)$ & $(0.0183)$ & $(0.0212)$ \\
Observations & 1,440 & 480 & 480 & 480 \\
Clusters & 12 & 4 & 4 & 4 \\
R-squared & 0.917 & 0.935 & 0.933 & 0.923 \\
\hline \multicolumn{5}{r}{ Robust standard errors in parentheses } \\
& $* * *$ p $<0.01, * *$ p $<0.05, *$ p $<0.1$ &
\end{tabular}

Table A.1: Pooled OLS regressions with the observed bid as the dependent variable using data from all treatments. Standard errors clustered at the subsession level.

\begin{tabular}{lcccccc}
\hline & $(1)$ & $(2)$ & $(3)$ & $(4)$ & $(5)$ & $(6)$ \\
& all & last 20 & $x_{i}<30$ & $x_{i}<30$ \& last 20 & $x_{i}>30$ & $x_{i}>30$ \& last 20 \\
\hline$x_{i}$ & $0.987^{* * *}$ & $0.988^{* * *}$ & $0.968^{* * *}$ & $0.975^{* * *}$ & $0.929^{* * *}$ & $0.908^{* * *}$ \\
& $(0.0127)$ & $(0.0128)$ & $(0.0207)$ & $(0.0164)$ & $(0.0218)$ & $(0.0347)$ \\
$\mathrm{R}$ & $0.740^{*}$ & 0.307 & $0.880^{*}$ & -0.0294 & 0.375 & 0.664 \\
$\mathrm{D} 5 \%$ & $(0.376)$ & $(0.437)$ & $(0.475)$ & $(0.483)$ & $(0.298)$ & $(0.536)$ \\
& $2.269^{* *}$ & $2.436^{* *}$ & $2.492^{* *}$ & $2.384^{*}$ & $2.175^{* * *}$ & $2.676^{* * *}$ \\
D25\% & $(0.846)$ & $(0.803)$ & $(0.973)$ & $(1.100)$ & $(0.662)$ & $(0.727)$ \\
& 0.172 & 0.351 & 0.394 & 0.0655 & -0.529 & 0.696 \\
Constant & $(0.447)$ & $(0.653)$ & $(0.576)$ & $(0.856)$ & $(0.675)$ & $0.476)$ \\
& $10.14^{* * *}$ & $10.43^{* * *}$ & $10.32^{* * *}$ & $10.68^{* * *}$ & $12.65^{* * *}$ & $13.52^{* * *}$ \\
\hline Observations & $(0.312)$ & $(0.302)$ & $(0.351)$ & $(0.329)$ & $(0.818)$ & $(1.398)$ \\
R-squared & 2,165 & 1,488 & 1,340 & 938 & 825 & 550 \\
Clusters & 0.909 & 0.923 & 0.757 & 0.791 & 0.631 & 0.666 \\
\hline \multicolumn{7}{c}{12} \\
\end{tabular}

Table A.2: Fixed effects regressions with bid as the dependent variable and the data restricted to bids within the signal and upper bound of the final use value. Standard errors clustered at the subsession level. 


\begin{tabular}{lcccccc}
\hline & $(1)$ & $(2)$ & \multicolumn{2}{c}{$(3)$} & $(4)$ & \multicolumn{2}{c}{$(5)$} & $(6)$ \\
& \multicolumn{2}{c}{ Auction Price } & \multicolumn{2}{c}{ Final Revenue } & Final Efficiency \\
& & last 20 & & last 20 & & last 20 \\
\hline$X_{(1)}$ & $0.0596^{* * *}$ & $0.0448^{* * *}$ & $0.117^{* * *}$ & $0.0891^{* * *}$ & $0.00606^{* * *}$ & $0.00547^{* * *}$ \\
& $(0.0107)$ & $(0.0140)$ & $(0.0229)$ & $(0.0207)$ & $(0.000820)$ & $(0.000695)$ \\
$X_{(2)}$ & $0.897^{* * *}$ & $0.923^{* * *}$ & $0.776^{* * *}$ & $0.776^{* * *}$ & $-0.00536^{* * *}$ & $-0.00621^{* * *}$ \\
& $(0.0230)$ & $(0.0336)$ & $(0.0515)$ & $(0.0664)$ & $(0.00118)$ & $(0.00143)$ \\
$\mathrm{R}$ & $1.873^{* * *}$ & $1.769^{*}$ & $1.889^{* * *}$ & $1.674^{*}$ & $0.0598^{* * *}$ & $0.0613^{* * *}$ \\
& $(0.546)$ & $(0.896)$ & $(0.507)$ & $(0.770)$ & $(0.00832)$ & $(0.00996)$ \\
D5\% & 1.466 & 1.197 & $-5.493^{* * *}$ & $-6.312^{* * *}$ & $-0.162^{* * *}$ & $-0.147^{* * *}$ \\
& $(0.926)$ & $(1.500)$ & $(0.488)$ & $(1.433)$ & $(0.0167)$ & $(0.0255)$ \\
D25\% & -1.324 & -1.337 & $-2.411^{* * *}$ & $-2.438^{*}$ & -0.0255 & -0.0220 \\
& $(0.794)$ & $(0.963)$ & $(0.770)$ & $(1.172)$ & $(0.0186)$ & $(0.0181)$ \\
max Safe & $-0.362^{*}$ & -0.383 & $-0.419^{* *}$ & -0.377 & $-0.0111^{*}$ & -0.0118 \\
& $(0.176)$ & $(0.257)$ & $(0.180)$ & $(0.272)$ & $(0.00571)$ & $(0.00765)$ \\
min Safe & -0.158 & 0.0302 & 0.0344 & 0.141 & 0.00856 & 0.00551 \\
& $(0.244)$ & $(0.364)$ & $(0.235)$ & $(0.379)$ & $(0.00536)$ & $(0.00785)$ \\
Constant & $12.01^{* * *}$ & $11.64^{* * *}$ & $11.52^{* * *}$ & $11.90^{* * *}$ & $0.855^{* * *}$ & $0.900^{* * *}$ \\
& $(1.577)$ & $(1.911)$ & $(1.350)$ & $(1.691)$ & $(0.0523)$ & $(0.0512)$ \\
\hline Observations & 813 & 577 & 813 & 577 & 813 & 577 \\
R-squared & 0.780 & 0.778 & 0.621 & 0.604 & 0.184 & 0.174 \\
Clusters & 12 & 12 & 12 & 12 & 12 & 12 \\
\hline
\end{tabular}

Robust standard errors in parentheses $* * * \mathrm{p}<0.01,{ }^{* *} \mathrm{p}<0.05,{ }^{*} \mathrm{p}<0.1$

Table A.3: Pooled OLS regressions with either auction price, final revenue, or final efficiency as the dependent variable. The data is restricted to and the data restricted to groups where neither bidder bid below signal or above the upper bound of the final use value Standard errors clustered at the subsession level. 


\begin{tabular}{|c|c|c|c|c|}
\hline & (1) & (2) & (3) & (4) \\
\hline & \multicolumn{2}{|c|}{ Final Earnings } & \multicolumn{2}{|c|}{ Final Losses } \\
\hline & & last 20 & & last 20 \\
\hline \multirow[t]{2}{*}{$x_{i}$} & $0.508^{* * *}$ & $0.464^{* * *}$ & 0.00723 & 0.00124 \\
\hline & $(0.0415)$ & $(0.0457)$ & $(0.0368)$ & $(0.0370)$ \\
\hline \multirow[t]{2}{*}{$\mathrm{R}$} & -0.981 & -0.108 & $6.061^{* *}$ & 1.167 \\
\hline & $(1.457)$ & (1.213) & $(2.375)$ & $(1.372)$ \\
\hline \multirow[t]{2}{*}{ D5\% } & $-2.363^{*}$ & -0.797 & $5.556^{* * *}$ & $5.883^{* * *}$ \\
\hline & $(1.265)$ & $(2.405)$ & $(0.809)$ & $(0.943)$ \\
\hline \multirow[t]{2}{*}{$\mathrm{D} 25 \%$} & -0.974 & 0.106 & 0.777 & $2.138^{*}$ \\
\hline & (1.191) & $(1.862)$ & $(0.551)$ & $(1.136)$ \\
\hline \multirow[t]{2}{*}{ Constant } & 1.410 & $1.958^{*}$ & $-6.830^{* * *}$ & $-6.885^{* * *}$ \\
\hline & (1.108) & $(1.150)$ & $(0.693)$ & $(0.778)$ \\
\hline Observations & 1,024 & 679 & 170 & 123 \\
\hline R-squared & 0.162 & 0.132 & 0.217 & 0.206 \\
\hline Clusters & 12 & 12 & 12 & 12 \\
\hline
\end{tabular}

Robust standard errors in parentheses

$* * * \mathrm{p}<0.01,{ }^{*} * \mathrm{p}<0.05,{ }^{*} \mathrm{p}<0.1$

Table A.4: Fixed effects regressions with bidder final earnings as the dependent variable and the data restricted to bids within the signal and upper bound of the final use value. Standard errors clustered at the subsession level. 